\title{
Strategies for College and University Instructional Physical Activity Program (IPAP) Directors
}

\author{
Bridget F. Melton ${ }^{1}$, Ed.D., Carrie Sampson Moore ${ }^{2} \&$ Brandi Hoffman $^{3}$ \\ ${ }^{1}$ Georgia Southern University, USA \\ ${ }^{2}$ Massachusetts Institute of Technology, USA \\ ${ }^{3}$ University of Minnesota, USA \\ Correspondence: Bridget F. Melton, Ed.D., Georgia Southern University, USA
}

Received: January 24, 2016

Accepted: February 3, 2016

Online Published: February 5, 2016

doi:10.5430/ijhe.v5n1p292

URL: http://dx.doi.org/10.5430/ijhe.v5n1p292

\begin{abstract}
There is a growing trend to rely on part-time instructors including both adjunct faculty and graduate teaching assistants (GTAs) in higher education (Eney \& Davidson, 2012). Most kinesiology departments depend on part-time instructors to teach instructional physical activity programs (IPAPs) to the general student population; this is historically referred to as basic instruction. These part-time instructors are content experts, but come from many different backgrounds. The purpose of this article is to highlight important topics for program coordinators, directors and faculty supervisors to consider including when training part-time instructors of instructional physical activity programs using a best practice approach. Three main area of concern will be addressed; adjusting to graduate school, classroom issues and teaching administrative duties. The use of effective strategies, such as orientation, mentoring, and teacher development for part-time instructors, will help ensure quality teaching and learning in physical activity programs.
\end{abstract}

Keywords: Graduate teaching assistants, Part-time instructors, Training, Instructional physical activity programs

\section{Introduction}

There is a growing trend to rely on part-time instructors including both adjunct faculty and graduate teaching assistants (GTAs) in higher education (Eney \& Davidson, 2012). Most kinesiology departments depend on part-time instructors to teach instructional physical activity programs (IPAPs) to the general student population historically referred to as basic instruction. These part-time instructors are content experts but come from many different backgrounds. The traditional model of physical education in the college and university setting has shifted from full time faculty and coaches to graduate assistants and adjunct instructors. Further, graduate assistants from other programs such as history and math may be assigned a graduate assistantship teaching instructional activity classes if they experience with a sport as a college athlete.

In addition, course offerings have expanded to include sections in the evening and special offerings such as martial arts and dance to meet students' interest and needs. Directors and Coordinators of IPAPs hire adjunct instructors that are qualified specialists with extensive teaching experience in a recreational setting such as studios or as a coach that may have a degree in fields such as sport management, sport psychology or business. Last, course management systems have become a mainstay of most universities and add complexity for instructors teaching in higher education. Consequently, graduate students may need an orientation to the town and school, as well as, teacher education training. The adjunct instructors that are recreational specialist and coaches joining the teaching team may need an orientation to the higher education setting that requires administrative tasks such as attendance, assessment, and use of content management system such as Blackboard. Accordingly, department-specific training for part time instructional physical activity instructors is needed. The aim of this article is to offer strategies IPAP directors and coordinators who have the complex task to provide effective training for part-time instructors. Specifically, key topics for effective strategies for orientation, mentoring, and teacher development for part-time instructors for quality teaching and learning will be introduced.

The purpose of this article is to highlight important topics for program coordinators, directors and faculty supervisors to consider including when training part time instructors of instructional physical activity programs using a best 
practice approach. Three main area of concern will be addressed: adjusting to graduate school, classroom issues and teaching administrative duties.

\section{Adjusting to Graduate School - Specific for Graduate Teaching Assistants (GTAs)}

\subsection{Orientation to Surroundings}

Many GTAs do not visit campus prior to the start of the school year, so they are unfamiliar with campus and their way around town. This can be problematic and impact their teaching because they are distracted and consumed with basic needs. Suggestions included:

\subsubsection{Tour of Campus}

This will orient students to their surroundings for the next 2-4 years. Also, familiarity helps instructors to guide undergraduate students who are may be lost. Ultimately, knowing where the library, health service, student union, food service and the campus recreation facilities are located on campus is essential.

\subsubsection{Tour of the Off-campus Community}

It is easy for graduate students to get lost in a new town, even with GPS. Providing a guided tour of the community, locating the local grocery store, shopping mall and local entertainment options will accelerate their connection to their new community. It is also important to point out, areas of town they should avoid.

\subsubsection{Community Magazine}

Community magazines or event guides are typically available at campus or at the local visitor bureau or welcome center and will provide them with a repository of recreational opportunities.

\subsection{Roommates and Housing}

Housing is a basic need that can impact a new graduate students experience and even their mental health.

\subsubsection{Housing Tip Sheet}

With the help of previous GTAs, a housing tip sheet is easy to create. GTAs generally want to live away from undergraduate student body, but close enough to bike to campus and in a safe neighborhood. Identifying for graduate students key neighborhoods and trusted real estate agents is invaluable.

\subsubsection{Send out a call for Roommate}

Simply sending an email and connecting the group of incoming and returning GTAs will facilitate communication of who needs roommates and who has a room.

\subsection{Hiring and Onboarding of Part-Time Instructors}

Universities are busy with all departments assisting with onboarding, part time instructions typically sometimes do not get priority for on board and commonly delays in processing paperwork occur.

\subsubsection{Start Early}

Planning ahead and identifying candidates early will help administrators move forward with the hiring process and provide everyone the opportunity to work through any issues that arise.

\subsubsection{On Boarding}

Make arrangements to have your human resource team reach out to your instructor prior to their campus arrival and attend a training session of your instructors. This direct contact may help avoid delayed payments and systemic issues.

\subsubsection{Mentoring System}

Pair new instructors with those with more experience. They can serve as a mentor and support them as they work through large and small issues. This also empowers the more experienced instructors and allows them to have some ownership over the training process.

\section{Critical Classroom Issues to Highlight for New Part Time Instructors}

\subsection{Scope and Sequence}

Many part time instructors are content experts, often with rich experience and hold a degree, but do not have a degree in education to know critical pedagogical components of creating a syllabi and lesson planning. As a result, the role of an instructor can be overwhelming. 


\subsubsection{Standard Syllabus}

A consistent syllabus for the instructors is helpful; one that has been reviewed by the university's instructional support center. In addition, there are many common issues related to ones' university/college that new instructors would have no idea about until they run into trouble such as parking, building access, dress code, equipment, health release, phone in classes, problem with course, student resources, student disabilities, policy on credit hours given etc. It is important to include these sorts of campus policies in the syllabus.

\subsubsection{Overview of Teaching for Semester}

Along with the syllabus, a unit plan or course outline can provide insight into the depth and scope of the course. Providing sample unit plans may help the new instructor understand one way of breaking down the course content, and show the skill progressions and then when game play begins. Many of our students just want to play a game, i.e. soccer or basketball, however it is important to develop and refine skills before playing games and tournaments.

\subsection{Progression}

Being a content expert does not always mean that the instructor knows how to break down skills for a novice learner.

\subsubsection{Sample unit Plans}

As mentioned before, progression is critical, is also important for the self-efficacy of the student. Providing unit plans that have been developed by an experienced instructor in the college setting will show the most efficient use of time given the experienced instructor knows the nuances of skill acquisition; this includes how fast certain skills are acquired and where additional practice and time is needed. Typically the unit plans are model that the instructors can adjust, however the instructors often do not make changes until they taught one semester or if they may have extensive coaching background and can identify adjustments to improve the learning.

\subsubsection{Teaching Demonstrations}

Cognitive knowledge of skill progression doesn't always translate into teaching appropriate progressions. New instructors benefit from practice teaching; that is writing a lesson plan for a typical class session and demonstrating 10-15 minutes of the lesson. This is a great opportunity to help instructors break down the skills in basic terms for the novice. It also allow for constructive feedback from the program directors and peers.

\subsection{Time on Task}

Developing the capacity for an instructor to teach to a large group will improve the student learning experience and increase instructor confidence.

\subsubsection{Time Management}

A simple do's and don'ts list helps an instructor pay attention to the critical aspects of good teaching. Because instructors have varied background, try not to assume anything. New instructors often go back to the way they were taught, which might not be the best practice. For example providing simple tips such as: if you are going to have line, no more than three people in a line; you must have enough equipment, 2:1 ration for students to balls; have a signal for start and stopping, whistle works great; back to the wall when teaching, and make sure everyone can see and hear you when teaching.

\subsubsection{Guest Speaker on Pedagogy}

There are numerous teaching approaches/models in the including: personalized system of instruction (Prewitt, Hannon, Colquitt, Brusseau, Newton, \& Shaw, 2015); sport education model (Pritchard, Hansen, Scarboro, \& Melnic, 2015); autonomy sport model (How Yew \& Wang Chee, 2016) and more for instructors to consider. Invite a physical education teacher education faculty member to lead an in-service on different pedagogical model. Certain classes lend themselves to specific models. It is ideal for classes focused on team sports to introduce of the sport education model or the personalize system of instruction. With fitness based classes the autonomy sport coaching model builds a system of trust/respect between instructor and students.

\subsection{Classroom Management}

Starting class with a professional tone helps instructors avoid issues later on in the semester. Students register for classes for varying reasons, reviewing the course content, policies and procedures let students know what to expect. 


\subsubsection{Syllabus}

Student conduct and behavior must be clearly outlines in the syllabus. Clear articulation of policies and procedures as well as repercussions provides the ground work for mutual respect, sets the tone for the class, and may negate issues with students and further provides documentation of expectations and consequences.

\subsubsection{Teaching Demonstrations of Challenging Situations}

Role playing difficult teaching situations can help new instructors prepare for challenges that may occur. The returning instructors can role play the typical classroom disruptions while the new instructors play the role of the teacher develop strategies for handling typically disruptions.

\subsubsection{Handbook}

Listing typical inappropriate student behavior in the instructor handbook can alert and prepare new instructors of how to handle disruptive student or common classroom issues from minor to more serious.

\subsubsection{Classroom Management Best Practices}

Many of the classroom issues can be reduced or limited by following best practices. Provide the NASPE Best Practices Guidelines for College and University Instructional Physical Activity Programs (Sweeney, Melton, Moore, \& Russell, 2008).

\subsection{Discipline Issues}

It is inevitable that there will be some behavior issue to address. These issues in the class are unpredictable can shake a new instructor's confidence.

\subsubsection{Open Door Policy}

Some problems will not be predictable, so the best way to equip new instructors is to let them know that the director is available to guide them through difficult situations. If something unusual occurs, they should talk with the director and together they will find a solution. Recently, mental health issues have become more prevalent in higher education (Keyes, Eisenberg, Perry, Dube, Kroenke, \& Dhingra, 2012) that impact students and may underline a behavior issue. It important to reassure instructors that student and instructor safety are paramount. Sometimes it is necessary to involve higher administration such as the dean of students or health services to address a student acting out in the class.

\subsubsection{Standard Syllabus}

The standard syllabus should have discipline policies in place. In addition, most universities include behavior expectations and discipline in the student conduct handbook which should be referred to in the syllabus with the direct link.

\subsubsection{Program Policies}

The instructor handbook is another place to keep the protocol for handling a problem and necessary communication including notifying the director. Common and unusual problems should be highlighted with corresponding action.

\subsubsection{Teaching Demonstration with Role Playing}

For the common discipline issues, role playing can really help the instructor/GTA develop strategies for handle these issue inside and outside the classroom.

\subsection{Assessment}

Although instructors are content experts they may not have experience with formal assessment of physical skills or testing of cognitive knowledge.

\subsubsection{Program Standards}

To ensure the overall integrity for the IPAP, it is important to have a consistent assessment protocol while noting that not that all testing is the same, but course grading rubric determined by group of experts in the education and sport should be used. Fitness and sport based classes will be assessed differently, that is, their distribution of cognitive, skill, and participation may not be equal. This is of course a critical part of the standard syllabus. 


\subsubsection{Skill Test Rubrics}

Typically using a skill testing rubric is not difficult for a new instructor that is a content expert; however, for instructors teaching a skill for the first time, it is challenging. Reviewing standardized rubrics with seasoned or new instructors teaching in a new course the first time is helpful.

\subsubsection{Cognitive Testing}

It is important for students to gain cognitive knowledge in addition to psychomotor skills during instructional physical activity courses, skill and cognitive progression is what differentiates academic courses from recreational instruction. Writing exams is a science that can be accomplished by novices simply by using test banks to help create exams. It is much easier to have a test bank to work from to tweak and adjust based on the class. Testing can also be done online to facilitate and save time grading, imputing grades, and posting grades that will preserve valuable time in class to practice and improve skills,

\subsubsection{Center for Teaching}

Many colleges have centers for teaching and learning for instructors and faculty to use. Employing a professional outside the field of Kinesiology to present to new part time instructors from this office may help instructors see the bigger picture and reinforce department efforts.

\section{Teaching Administrative Duties}

\subsection{Email System}

Although young graduate teaching assistants may be very familiar with technology, other part time instructor may not be acquainted with the universities preferred technology system such as email and course management system. Regardless, there is still a learning curve to use technology to its full potential.

\subsubsection{Email Training Session}

Most universities have a technology center that can provide training session on the functionality of the email system, including best practices of email, organizing, storing, linking to calendars, Google docs, Google hangout and so on. Confirming or training part time instructors on email is essential as is a fundamental communication tool especially for those instructors who are only on campus to teach a few days and hours a week.

\subsection{Learning/Course Management System (LMS)}

Learning management systems are a new and important part of higher education. They serve as virtual office of sort for part time instructors. It is essential to provide access, training and support for new part time instructors as these systems are usually university specific. However, learning management systems add to the complexity of the role of a teacher and accordingly IPAP directors/coordinators must understand and facilitate the learning and use of the system for their courses.

\subsubsection{Instructor Access}

Access is critical however new instructors and graduate teaching assistance may not have access until must they are complete the hiring process or graduate school admissions. It is imperative to work with LMS administration, human resources and graduate admissions during summer to make sure all paper is processed before the new instructors arrive on campus.

\subsubsection{Administrator Access}

Many schools provide administrator assess to all departmental or program level courses so the IPAP director can access if needed. At times this will be extremely useful to monitor communication by instructors, access student grades when needed and assist an instructor who having difficulty.

\subsubsection{Maintain Good Relationship with Instructional Technology Staff (IT)}

Keeping in contact with the IT team that supports the LMS is recommended. Offering the IT staff with feedback of success and concern about the LMS will enable the IT staff to support your department's efforts. Further, the summer is a good time to provide a profile of your incoming instructors before there focus shifts to starting the fall semester.

\subsection{LMS Training}

LMS systems are customized and used in a particular on each campus so training is necessary. 


\subsubsection{Online Orientation}

Prior to arriving on campus, require new instructors to become familiar with the basic components of the LMS: grade book, assignments/homework, assessments/test, news blast/post, email, etc. Simply send the link and a list of the components they should review.

\subsubsection{In Person Sessions}

Hands on training is invaluable, most of individual learn by doing and that is what is most beneficial for part time instructors. A working meeting to populate the LMS, including posting welcome notice, uploading pictures, syllabus and unit plans is an effective way to orient new instructors. Other topics that would be important to address are setting up exams, final grades and using optional features of the LMS.

\subsubsection{Mentoring System}

It is difficult for directors/coordinators to meet on-one with all new their instructors to ensure their questions are answered. However, assigning a buddy or mentor to new instructors will facilitate learning and provide an additional contact for a new instructor throughout their first year.

\subsection{Departmental Standard Use of LMS}

Clarity for students is key to maximize the use of a LMS.

\subsubsection{Consistent Online Course Set Up}

Because students will have dozen of classes that use the online LMS so without some standardization, using different sites can become confusing for students. It is important to also provide the instructor parameters to tailor their sites and express their academic freedom. In short, keep it simple and clear.

\subsubsection{Critical Elements}

Welcome - a welcome to introduce the instructor, course and learning outcomes.

Check sheet - a step by step sheet to sure they completed all of the learning activities.

Syllabus - program approved syllabus.

Unit plan- a weekly guide of topics, activities and assignments.

Communication rules - Instructor's preferred email, response time, in-case of emergency.

Technology Requirement - Recommended/compatible browsers and software with LMS.

Learning Needs - Post the universities statement of support for students with disabilities and available learning assistance.

\subsection{Content Specific Issues}

New instructors may be interested in personalizing their course, however content errors can occur if they deviate too far beyond standard syllabi.

\subsubsection{Consistent Modules}

When setting up modules, establish a standard and enforce consistency in what is included such as introduction, check sheet, study guides or content, quiz, discussion etc.

\subsubsection{Modifiable}

All good instructors are going want to add to a standard course, which is encouraged. Provide direction where information or components can be added such as links or videos while maintaining the standard set up.

\subsubsection{Review Materials}

Most published textbook, test banks and instructor material have some kind of error. Most publishing or content provider welcome this type of information. Fortunately, online materials can be correct seamlessly.

\section{Discussion}

The growing trend to hire part-time or adjunct instructors to supplement faculty to teach instructional physical activity courses requires new specific orientation and training programs to maintain quality instruction. The lack of physical education graduate assistants has required kinesiology departments to broaden their instructor team to include graduate assistance from other disciplines within Kinesiology, other graduate programs within the university and to degreed content experts from coaching and recreation setting that may not have a pedagogical background in 
physical education. Logically, graduate teaching assistants have slightly different but overlapping needs with part time instructors from coaching or recreation.

It is critical to assist a young graduate teaching assistants to adjust to their new community and university (Boyle \& Boice, 1998). Orientation can take many forms but the key components for effective orientation include a systematic intentional approach involving the instructors input and participation to insure new instructors feel connected to their new university. In addition, effective orientation can be extremely important to long-term success with new instructor motivation and retention (Aguinis \& Kraiger, 2009; Blanchard, 1999). In short, a position specific orientation directed at graduate teaching assistants including housing and key stores in the community can help new instructors be organized and ready to engage in their graduate program as well as teach instructional activity courses.

Systematic intentional training for all new instructors is equally important. Both graduate assistants and part-time instructors (recreational specialist and coaches) generally require a pre- service training to the universities specific administrative responsibilities such as course management system used by the university but also critical topics in teaching education (Barker, Felstehausen, Couch, Henry, 1997). Research has demonstrated the importance of in-person training of by an expert or peer for the transference of policies, procedures and training such as presented in this article into teaching in the gym, field or pool (Sparks \& Loucks-Horsley, 1989). Further, support is necessary for effective instructor development. Sparks \& Loucks-Horsley (1989) conclude that study after study confirm the necessity to establish support mechanisms such as establishing norms that encourage collegiality and experimentation, clarifying goals and expectations, assist instructors making changes to adapt to norms and expectations including follow up through their second course while framing and focusing training on practices that improve student learning as the goal. It is worth emphasizing that mentoring is an invaluable component of training that can facilitate ongoing follow up (Boyle \& Boice, 1998).

Bringing instructors with various backgrounds together for training provides a unique opportunity for them to learn from each other. Because today's instructors leading instructional physical activity courses come from various kinesiology fields including exercise science, sport management, recreation, coaching as well as other fields graduate students may be perusing provides a unique forum for training and mentoring. This rich pluralistic environment can provide a forum to hear teaching advice from the diverse voices of those teaching instructional activities (Kezar, 2001). Specifically, seasoned instructors can be paired with new graduate teaching assistants to share best practices around classroom management where the seasoned instructor is likely to take the lead. Similarly, with a the same partners to review use of email or the course management system, the graduate teaching assistant, likely a native to current technology, may take the lead.

The use of effective strategies, such as orientation, mentoring, and teacher development for part-time instructors, will help ensure quality teaching and learning in physical activity programs. It important to note that much of the staff development literature is theoretical and descriptive rather than experimental, (Sparks \& Loucks-Horsley, 1989) revealing an interesting area for future research in Kinesiology. Specifically, further research on successful orientation and training programs of part time instructors with diverse backgrounds is needed and possible within kinesiology instructional physical activity programs.

\section{References}

Aguinis, H., \& Kraiger, K. (2009). Benefits of training and development for individuals and teams, organizations, $\begin{array}{lllll}\text { and society. Annual review of psychology, } & 60, & 451-474 .\end{array}$ http://dx.doi.org/10.1146/annurev.psych.60.110707.163505

Barker, S., Felstehausen, G., Couch, S., \& Henry, J. (1997). Orientation programs for older and delayed-entry graduate students. Journal of Student Affairs Research and Practice, 35(1), 57-68. http://dx.doi.org/10.2202/1949-6605.1037

Blanchard, P. N. (1999). Effective Training, Systems, Strategies, and Practices, 4/e. Pearson Education India.

Boyle, P., \& Boice, B. (1998). Systematic mentoring for new faculty teachers and graduate teaching assistants. Innovative Higher Education, 22(3), 157-179. http://dx.doi.org/10.1023/A:1025183225886

Eney, P. R., \& Davidson, E. (2012). Improving Supervision of Part-Time Instructors. Journal Of Developmental Education, 36(2), 28-39.

How Yew, M., \& John Wang Chee, K. (2016). The effectiveness of an AutonomySupportive Teaching Structure in Physical Education. / Eficacia de la estructura de enseñanza con soporte de autonomía en educación física. RICYDE. Revista Internacional De Ciencias Del Deporte, 12(43), 528. 
Kezar, A. (2000). Pluralistic leadership: Incorporating diverse voices. Journal of Higher Education, 722-743. http://dx.doi.org/10.2307/2649160

Keyes, C. M., Eisenberg, D., Perry, G. S., Dube, S. R., Kroenke, K., \& Dhingra, S. S. (2012). The relationship of level of positive mental health with current mental disorders in predicting suicidal behavior and academic impairment in college Students. Journal Of American College Health, 60(2), 126-133. http://dx.doi.org/10.1080/07448481.2011.608393

Prewitt, S., Hannon, J. C., Colquitt, G., Brusseau, T. A., Newton, M., \& Shaw, J. (2015). Implementation of a personal fitness unit using the personalized system of instruction model. Physical Educator, 72(3), 382-402.

Pritchard, T., Hansen, A., Scarboro, S., \& Melnic, I. (2015). Effectiveness of the sport education fitness model on fitness levels, knowledge, and physical activity. Physical Educator, 72(4), 577-600. http://dx.doi.org/10.18666/TPE-2015-V72-I4-6568

Sparks, D., \& Loucks-Horsley, S. (1989). Five models of staff development. Journal of staff development, 10(4), 40-57.

Sweeney, S., Melton, Moore, C. \& Russell, J., (2008). Best practices guidelines for college and university instructional physical activity programs. National Associate of Sport and Physical Education [NASPE]: Restin, Virginia.

Wuest, D. A., \& Bucher, C. A. (2009). Foundations of physical education, exercise science, and sport. McGraw-Hill Higher Education: New York, NY. 